\title{
Bismuth nitrate pentahydrate-induced novel nitration of eugenol
}

\author{
Luis Canales ${ }^{\dagger}$, Debasish Bandyopadhyay ${ }^{\dagger}$ and Bimal K Banik
}

\begin{abstract}
Background: Eugenol, the main constituent of clove oil possesses a number of medicinal activities. To enhance the medicinal property, structural modification is required. On the other hand, bismuth nitrate pentahydrate has been established as an excellent eco-friendly nitrating agent for several classes of organic compounds.

Results: Bismuth nitrate pentahydrate-induced nitration of eugenol has been investigated very thoroughly. Twenty five different conditions have been studied. The microwave-induced solvent-free reaction has been identified as the best condition.

Conclusions: Spectral analyses confirm that 5-nitroeugenol is the sole product in all the cases. No oxidized or isomerized product could be detected.
\end{abstract}

\section{Background}

Syzygium aromaticum L., popularly known as clove, belongs to the plant family Myrtaceae, and has been used in folk medicine and dental treatment. Eugenol (4-allyl-2methoxyphenol), the main component of clove oil, is an allyl chain-substituted guaiacol in the biosynthesized phenylpropanoid compound class derived from Syzygium aromaticum L. and widely used in medicine [1]. It is widely cultivated in India, Indonesia, Sri Lanka, Madagascar, and Brazil. In addition, it is commonly used in root canal and temporary fillings; it shows antibacterial activity, and helps in dental caries treatment and periodontal disease $[2,3]$. Clove oil has been successfully used for some breath problems [3]. It is slightly soluble in water and soluble in organic solvents. A recent report [4] reveals the insecticidal effect of eugenol. Anti-inflammatory and antinociceptive activities of eugenol have also been reported [5]. Moreover, eugenol is reported to possess antioxidant and anticancer properties [6].

In order to study the biological activities of eugenol derivatives, nitration by conventional nitric acid-sulfuric acid or a nitronium tetrafluoborate method were performed. These reactions require a mixture of concentrated or fuming nitric acid with sulfuric acid leading to excessive use of

\footnotetext{
* Correspondence: banik@utpa.edu

† Contributed equally

Department of Chemistry, The University of Texas-Pan American, 1201, West University Drive, Edinburg, TX 78539, USA
}

hazardous chemicals [7]. Nitration of eugenol and its derivatives was reported using $\mathrm{HNO}_{3} / \mathrm{H}_{2} \mathrm{SO}_{4}$ [8] or by $\mathrm{HNO}_{3} /$ $\mathrm{Et}_{2} \mathrm{O}$ [9]. In addition, difficult work-up procedure and low yield were also observed as a result of some other side reactions.

On the other hand, the usefulness of clay-mediated organic synthesis has been documented in a large number of publications which includes Michael addition [10], regioselective synthesis of carbazoles [11], selective hydrolysis of nucleosides [12], and Knoevenagel/hetero Diels-Alder reaction [13]. We have demonstrated the use of trivalent bismuth nitrate pentahydrate in organic synthesis. These experiments have resulted in various methods that include protection of carbonyl compounds [14], Michael reaction [15], nitration of aromatic systems [16], deprotection of oximes and hydrazones [17], and Paal-Knorr synthesis of pyrroles [18]. Our success in the bismuth nitrate-induced reaction has revealed [19] that this reagent acts as a Lewis acid.

We have been studying metal/metal salts-mediated reactions with the aim of developing several biologically active compounds; including anticancer polyaromatic compounds [20] and anticancer $\beta$-lactams [21]. Toward this goal, we also demonstrated that an effective bismuth nitrate-mediated nitration of polycyclic aromatic hydrocarbons. We reported the nitration of estrone with metal salts which exclusively depends on the nature of the solid surfaces [22]. Herein we report the direct nitration of 
eugenol using bismuth nitrate pentahydrate, an economical, easily available and eco-friendly salt. A comparison with various solvents, solid supports along with solventfree condition has been carried out.

\section{Results}

In previous work we reported the nitration of estrone with different types of metal salts in the presence of solid surfaces under various conditions [22]. It has been clearly established that the nitration reaction induced by metal salts depend on the nature of the solid surface, nitrating agents, and reaction conditions. We have extensively studied the nitration of eugenol using various methods and solid surfaces (Figure 1). The results are summarized in Table 1.

\section{Discussion}

Bismuth nitrate pentahydrate is the metal nitrate used in this experimentation process, although the effect of many others such as CAN, $\mathrm{Zn}\left(\mathrm{NO}_{3}\right)_{2}, \mathrm{Ca}\left(\mathrm{NO}_{3}\right)_{2}, \mathrm{LaNO}_{3}$, $\mathrm{NaNO}_{3}$, and $\mathrm{Cu}\left(\mathrm{NO}_{3}\right)_{2}$ were also studied elsewhere. Bismuth nitrate pentahydrate was confirmed as the best nitrating agent among all others. Dry conditions and solvent-free methods along with commercial solvents without any purification were investigated in order to identify the best conditions for this reaction. Reactions were performed at high temperature using Dean-Stark water separator, traditional reflux, and conventional kitchen microwave-induced methods. Solid surfaces such as florisil, silica gel, molecular sieves, KSF clay, and neutral alumina were used as solid support in the reaction. It was discovered that silica gel is the best solid surface. In some cases (entries 2, 17 and 22), the reaction gave 100\% yield of the product (4-allyl-2-methoxy-5-nitrophenol). Eugenol and bismuth nitrate along with KSF clay as solid support, under the conventional microwave and solvent-free condition produced $100 \%$ yield (entry 19). Quantitative yield was also observed under reflux in benzene with bismuth nitrate in presence of silica gel (entry 22). No reaction was observed when $\mathrm{Bi}\left(\mathrm{NO}_{3}\right)_{3}$ was used at room temperature even after $24 \mathrm{~h}$ (entries 11-15).

\section{Conclusions}

In conclusion, metal nitrate-induced nitration of eugenol has been successfully carried out under various conditions and the formation of a single product (4-allyl-2-methoxy- 5-nitrophenol) has been observed in variable yields. The exploratory results described herein confirm that bismuth nitrate pentahydrate is the reagent of choice in the absence of any solvent under microwave-irradiation condition (entry 19). Importantly, in contrast with nitric acidmediated method, these reactions mediated by bismuth nitrate have several important characteristics. For example, no isomerization of the alkene moiety has been observed, regioselectivity remains identical irrespective of the solid supports and conditions, no oxidation of the alkene/aromatic systems has been observed, and phenolic hydroxyl group has no influence on the regioselectivity of the reactions. On the basis of these important and selective observations, this method will find very useful applications in synthetic chemistry of electrophilic aromatic nitration reaction.

\section{Methods}

\section{General}

FT-IR spectra were registered on a Bruker IFS 55 Equinox FTIR spectrophotometer as $\mathrm{KBr}$ discs. ${ }^{1} \mathrm{H}-\mathrm{NMR}$ $(600 \mathrm{MHz})$ and $13 \mathrm{C}-\mathrm{NMR}(125 \mathrm{MHz})$ spectra were obtained at room temperature with Bruker-600 equipment using TMS as internal standard and $\mathrm{CDCl}_{3}$ as solvent. Analytical grade chemicals (Sigma-Aldrich Corporation) were used throughout the project. Deionized water was used for the preparation of all aqueous solutions.

\section{General procedure for the nitration of Eugenol}

In general, eugenol $(1 \mathrm{mmol})$ and bismuth nitrate pentahydrate ( 1 eqv.) were mixed and the mixture was studied under different conditions varying the method, solid support and/or solvent as mentioned in Table 1. A representative experimental procedure (entry 2 ) is as follows: Eugenol $(1 \mathrm{mmol})$ and silica gel $(500 \mathrm{mg})$ was added to a suspension of bismuth nitrate pentahydrate ( 1 eqv.) in dry benzene $(20 \mathrm{~mL})$. The mixture was refluxed using DeanStark water separator for $2 \mathrm{~h}$. The progress of the reaction was monitored by TLC. The reaction mixture was then repeatedly extracted $(3 \times 10 \mathrm{~mL})$ with dichloromethane, washed with saturated solution of sodium bicarbonate, brine and water successively. The organic layer was dried over anhydrous sodium sulfate and concentrated to afford the crude product which was purified by column chromatography (silica gel, hexane/ethyl acetate).

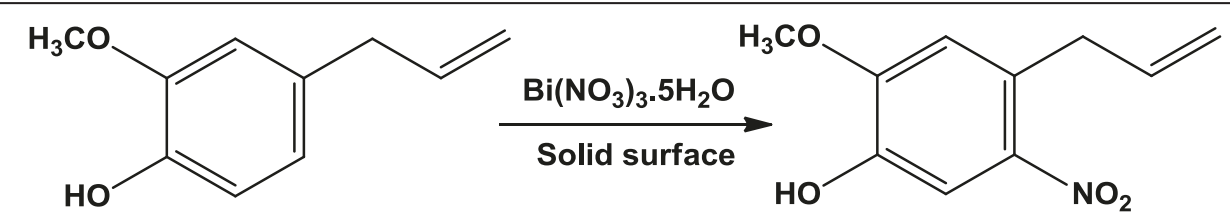

Figure 1 Nitration of eugenol with bismuth nitrate on solid surface. 
Table 1 Bismuth nitrate-induced nitration of eugenol under different conditions

\begin{tabular}{|c|c|c|c|}
\hline Entry & Solid surface & Method/Solvent & Yield (\%) \\
\hline 1 & Florisil & Dean-Stark/Benzene & 75 \\
\hline 2 & Silica gel & Dean-Stark/Benzene & 100 \\
\hline 3 & Molecular sieves & Dean-Stark/Benzene & 80 \\
\hline 4 & KSF clay & Dean-Stark/Benzene & 95 \\
\hline 5 & Neutral alumina & Dean-Stark/Benzene & 90 \\
\hline 6 & Florisil & Reflux/DCM & 80 \\
\hline 7 & Silica gel & Reflux/DCM & 90 \\
\hline 8 & Molecular sieves & Reflux/DCM & 80 \\
\hline 9 & KSF clay & Reflux/DCM & 92 \\
\hline 10 & Neutral alumina & Reflux/DCM & 84 \\
\hline 11 & Florisil & Dry & NR \\
\hline 12 & Silica gel & Dry & $N R^{*}$ \\
\hline 13 & Molecular sieves & Dry & NR \\
\hline 14 & KSF clay & Dry & $\mathrm{NR}$ \\
\hline 15 & Neutral alumina & Dry & NR \\
\hline 16 & Florisil & Microwave/Solvent Free & 90 \\
\hline 17 & Silica gel & Microwave/Solvent Free & 100 \\
\hline 18 & Molecular sieves & Microwave/Solvent Free & 95 \\
\hline 19 & KSF clay & Microwave/Solvent Free & 100 \\
\hline 20 & Neutral alumina & Microwave/Solvent Free & 92 \\
\hline 21 & Florisil & Reflux/Benzene & 83 \\
\hline 22 & Silica gel & Reflux/Benzene & 100 \\
\hline 23 & Molecular sieves & Reflux/Benzene & 85 \\
\hline 24 & KSF clay & Reflux/Benzene & 95 \\
\hline 25 & Neutral alumina & Reflux/Benzene & 92 \\
\hline
\end{tabular}

*No reaction.

\section{4-Allyl-2-methoxy-5-nitrophenol}

sticky mass; IR ( $\mathrm{KBr}$ disc, $\mathrm{cm}^{-1}$ ): 2369, 1522, 1457, 1243, 1136, 1061, 941, 810 and 712; ${ }^{1} \mathrm{H}$ NMR $\left(\mathrm{CDCl}_{3}, 600 \mathrm{MHz}\right)$ $\delta: 10.67(\mathrm{~s}, 1 \mathrm{H}), 7.45(\mathrm{~s}, 1 \mathrm{H}), 6.84(\mathrm{~s}, 1 \mathrm{H}), 5.89(\mathrm{~m}, 1 \mathrm{H})$, $5.05(\mathrm{~m}, 2 \mathrm{H}), 3.83(\mathrm{~s}, 3 \mathrm{H}), 3.27(\mathrm{~d}, 2 \mathrm{H}, J=1.1 \mathrm{~Hz}) .{ }^{13} \mathrm{C}$ NMR $\left(\mathrm{CDCl}_{3}, 125 \mathrm{MHz}\right) \delta: 149.86,144.88,135.94,133.64$, 132.46, 128.63, 127.43, 125.07, 56.70, 36.74.

\section{Acknowledgements}

We gratefully acknowledge the funding support from National Cancer Institute (NIH/NCI-P20, Grant\# 5P20CA138022-02).

\section{Competing interests}

The authors declare that they have no competing interests.

Received: 24 March 2011 Accepted: 20 September 2011 Published: 20 September 2011

\section{References}

1. dos Santos AL, Chierice GO, Riga AT, Alexander K, Matthews E (2009) Thermal behavior and structural properties of plant-derived eugenyl acetate. J Therm Anal Calorim 97:329-332. doi:10.1007/s10973-008-9753-0.
2. Cai L, Wu CD (1996) Compounds from Syzygium aromaticum possessing growth inhibitory activity against oral pathogens. J Nat Prod 59:987-990. doi:10.1021/np960451q

3. Lee KG, Shibamoto $T$ (2001) Antioxidant property of aroma extract isolated from clove buds [Syzygium aromaticum]. Food Chem 74:443-448. doi:10.1016/S0308-8146(01)00161-3.

4. Han Q-X, Huang S-s (2009) The bioactivity of eugenol against the red flour beetle Tribolium castaneum. Chongqing Shifan Daxue Xuebao, Ziran Kexueban 26:16-19

5. Daniel AN, Sartoretto SM, Schmidt GC, Caparroz-Assef SM, Bersani-Amado CA, Cuman RKN (2009) Anti-inflammatory and antinociceptive activities of eugenol essential oil in experimental animal models. Revista Brasileira de Farmacognosia 19:212-217. doi:10.1590/50102-695X2009000200006.

6. Carrasco AH, Espinoza CL, Cardile V, Gallardo C, Cardona W, Lombardo L, Catalan MK, Cuellar FM, Russo A (2008) Eugenol and its synthetic analogues inhibit cell growth of human cancer cells. Part 1. J Brazilian Chem Soc 19:543-548. doi:10.1590/50103-50532008000300024.

7. Lunar L, Sicilia D, Rubio S, Perez-Bendito D, Nickel U (2000) Degradation of photographic developers by Fenton's reagent: condition optimization and kinetics for metol oxidation. Water Res 34:1791-1802. doi:10.1016/500431354(99)00339-5.

8. Clemo GR, Turnbull JH (1949) Nitration of some derivatives of eugenol. J Chem Soc 1870-1871

9. Andersen $L$ (1956) Nitration of phenols with carbon-containing substituents. Suomen Kemistiseuran Tiedonantoja 65:17-18

10. Chakrabarty M, Sarkar S (2002) Novel clay-mediated, tandem additionelimination-(Michael) addition reactions of indoles with 3-formylindole: an eco-friendly route to symmetrical and unsymmetrical triindolylmethanes. Tetrahedron Lett 43:1351-1353. doi:10.1016/50040-4039(01)02380-2.

11. Chakrabarty M, Ghosh N, Harigaya Y (2004) A clay-mediated, regioselective synthesis of 2-(aryl/alkylamino)thiazolo[4,5-c]carbazoles. Tetrahedron Lett 45:4955-4957. doi:10.1016/j.tetlet.2004.04.129.

12. Gurjar MK, Mondal D, Ravindranath SV, Chorghade MS (2006) Clay-mediated selective hydrolysis of 5'-O-acetyl-2',3'-isopropylidene/cyclohexylidene nucleosides. Synth Commun 36:2321-2327. doi:10.1080/00397910600639968.

13. Ramesh E, Raghunathan R (2009) Microwave-assisted K-10 montmorillonite clay-mediated Knoevenagel hetero-Diels-Alder reactions: a novel protocol for the synthesis of polycyclic pyrano[2,3,4-k] xanthene derivatives. Synth Commun 39:613-625. doi:10.1080/00397910802417825.

14. Srivastava N, Dasgupta SK, Banik BK (2003) A remarkable bismuth nitratecatalyzed protection of carbonyl compounds. Tetrahedron Lett 44:1191-1193. doi:10.1016/50040-4039(02)02821-6.

15. Srivastava N, Banik BK (2003) Bismuth Nitrate-Catalyzed Versatile Michael Reactions. J Org Chem 68:2109-2114. doi:10.1021/j0026550s.

16. Banik BK, Samajdar S, Banik I, Ng SS, Hann J (2003) Montmorillonite impregnated with bismuth nitrate: Microwave-assisted facile nitration of $\beta$ lactams. Heterocycles 61:97-100. doi:10.3987/COM-03-S62

17. Banik BK, Adler D, Nguyen P, Srivastava N (2003) A new bismuth nitrateinduced stereospecific glycosylation of alcohols. Heterocycles 61:101-104. doi:10.3987/COM-03-S63.

18. Rivera S, Bandyopadhyay D, Banik BK (2009) Facile synthesis of Nsubstituted pyrroles via microwave-induced bismuth nitrate-catalyzed reaction. Tetrahedron Lett 50:5445-5448. doi:10.1016/j.tetlet.2009.06.002.

19. Banik BK, Reddy AT, Datta A, Mukhopadhyay C (2007) Microwave-induced bismuth nitrate-catalyzed synthesis of dihydropyrimidones via Biginelli condensation under solventless conditions. Tetrahedron Lett 48:7392-7394. doi:10.1016/j.tetlet.2007.08.007.

20. Banik BK, Becker FF (2001) Synthesis, electrophilic substitution and structure-activity relationship studies of polycyclic aromatic compounds towards the development of anticancer agents. Curr Med Chem 8:1513-1533

21. Banik I, Becker FF, Banik BK (2003) Stereoselective Synthesis of $\beta$-Lactams with Polyaromatic Imines: Entry to New and Novel Anticancer Agents. J Med Chem 46:12-15. doi:10.1021/jm0255825

22. Bose A, Sanjoto WP, Villarreal S, Aguilar H, Banik BK (2007) Novel nitration of estrone by metal nitrates. Tetrahedron Lett 48:3945-3947. doi:10.1016/j. tetlet.2007.04.050.

doi:10.1186/2191-2858-1-9

Cite this article as: Canales et al:: Bismuth nitrate pentahydrate-induced novel nitration of eugenol. Organic and Medicinal Chemistry Letters 2011 1:9. 